Discussion Paper Series A No.718

\title{
International Exploitation, Capital Export, and Unequal Exchange
}

\author{
Jonathan F. Cogliano \\ (Economics Department, University of Massachusetts Boston) \\ Soh Kaneko \\ (Faculty of Economics, Oita University) \\ Roberto Veneziani, \\ (School of Economics and Finance, Queen Mary University of London) \\ and \\ Naoki Yoshihara \\ (Department of Economics, University of Massachusetts Amherst, \\ Institute of Economic Research, Hitotsubashi University and \\ School of Management, Kochi University of Technology)
}

Institute of Economic Research Hitotsubashi University

Kunitachi, Tokyo, 186-8603 Japan 


\title{
International Exploitation, Capital Export, and Unequal Exchange
}

\author{
Jonathan F. Cogliano, ${ }^{*}$ Soh Kaneko, ${ }^{\dagger}$ \\ Roberto Veneziani, ${ }^{\ddagger}$ and Naoki Yoshihara ${ }^{\S}$
}

November 30, 2020

\begin{abstract}
We discuss how international exploitation and unequal exchange emerge in the global economy by focusing on simple economic models with and without credit markets. Free trade of commodities among rich and poor countries results in a transfer of labor time between countries, allowing the citizens of some countries to consume more of the world's social labor than they have contributed. Capital movements across borders together with strong restrictions on the movement of people result in net exporters of capital exploiting (or benefiting from unequal exchange at the expense of) net capital importers. Under perfect competition, mutual benefits from free trade in goods and capital can coexist alongside unequal flows of revenue and labor in the world economy. Market imperfections and the open use of coercion are not necessary for international exploitation to emerge. However, they may be central for it to persist over time.
\end{abstract}

JEL: B51 (Socialist, Marxian, Sraffian); D63 (Equity, Justice, Inequality, and Other Normative Criteria and Measurement); C63 (Computational Techniques, Simulation Modeling); F21 (International Investment, Long-Term Capital Movements); F54 (Colonialism, Imperialism, Postcolonialism).

Keywords: Unequal exchange, class, capital flows, global economy.

*(Corresponding author) Economics Department, University of Massachusetts Boston, Wheatley Hall, 5th floor, 100 William T. Morrissey Blvd., Boston, MA 02125, U.S. (jonathan.cogliano@umb.edu)

${ }^{\dagger}$ Faculty of Economics, Oita University, Dannoharu 700, Oita-city, Oita 870-1192, Japan (skaneko@oitau.ac.jp)

${ }^{\ddagger}$ School of Economics and Finance, Queen Mary University of London, Mile End Road, London E1 4NS, UK. (r.veneziani@qmul.ac.uk)

$\S$ Department of Economics, University of Massachusetts Amherst, Crotty Hall, 412 North Pleasant Street, Amherst, MA 01002, U.S.; The Institute of Economic Research, Hitotsubashi University, Naka 2-1, Kunitachi, Tokyo 186-8603, Japan; and School of Management, Kochi University of Technology, 2-22, Eikokuji-Chou, Kochi, Kochi, 780-8515, Japan. (nyoshihara@econs.umass.edu) 


\section{Introduction}

It is difficult to overlook the large inequalities across countries in income per capita and in output per worker that characterize the global economy. Indeed, empirical studies of longrun historical data show that inequality in per capita income between countries has been expanding since 1820 (see Maddison [17]). It should therefore come as no surprise that a central topic in economics has been the study of the mechanisms generating such persistent, if not widening, disparity between rich and poor countries.

According to the 'convergence theory' (or 'catch-up theory) in standard macroeconomics, if all countries have access to the same production techniques and are able to trade freely, then per capita incomes in poorer countries will catch up with richer countries. For, given that technology is characterised by diminishing returns, countries with low capital per capita can grow faster. As a result, in the long run all countries converge to the same level of per capita income (more precisely, income per hours worked). Similarly, the neoclassical HeckscherOhlin-Samuelson (HOS) theory of international trade emphasizes that both rich and poor countries enjoy mutual gains from trade due to the principle of comparative advantage.

In other words, in the mainstream approach to international economics, trade can only be mutually beneficial and growth inducing, and unfettered competition has a built-in equalizing effect. From this perspective, inequalities between countries, uneven development and the emergence of a hierarchy in the world economy can only be explained by some forms of market failure, such as the presence of externalities and/or market imperfections - arising, for example, from increasing returns to scale, as in Krugman [16], or borrowing constraints in international financial markets, as in Matsuyama [20].

This view stands in stark contrast to the radical and Marxian analysis of the global economy. In Chapter 22 of Capital I, Marx [18] argues that international labor productivity differentials imply that the domestic labor values of commodities in rich countries are lower than those in poor ones. In this context, the free trade of commodities across borders yields an unequal exchange of labor (UE, hereafter): rich countries sell commodities embodying less labor in exchange for commodities with higher labor content, and vice versa for poor countries.

This is a corollary of the Ricardian theory of international trade (Ricardo [23]), where free trade is governed by the principle of comparative advantage. Given that countries have access to different technologies, domestic commodity prices that are determined by labor-value pricing will differ in autarkic conditions. However, they will converge to an international (equilibrium) price system once commodities are freely traded on global markets. Thus, in the Ricardian case, inequalities emerge from competitive behavior and free trade.

Unlike in the Ricardian setting, Arghiri Emmanuel [9] supposes that all countries have access to the same technology, but, due to significant barriers to migration and differences in labor market institutions, wage differentials persist across borders. He then shows that assuming free trade in international goods markets and perfect capital mobility, profit rates equalize across countries, and this causes transfers of surplus labor from poor countries with lower capital-labor ratios to rich countries with higher capital-labor ratios, and thereby widens the wealth gap. This is the celebrated theory of unequal exchange, one of the most influential elaborations of Marx's theory in Ch. 22 of Capital I.

In the world-systems perspective adopted by Emmanuel, the capitalist world economic 
system is characterized by a core-periphery structure in which the periphery is economically subordinate to the core. Peripheral countries, which historically comprised underdeveloped countries and former colonies, play a complementary role which fosters capital accumulation in the core by providing raw materials and low-cost crops. The plantation economy accompanied with the pre-modern slavery is a typical historical example of the periphery economy, whose economic development was dependent on the capital accumulation in the core, and in which wage disparity between the core and the periphery was institutionalized. ${ }^{1}$ Emmanuel's analysis accurately captures important aspects of the historical reality of North-South economic relations after World War II.

Given the institutionalized wage disparity and profit rate equalization via capital mobility across borders, the international free trade of commodities is characterized by complete specialization in equilibrium: capital-rich core countries specialize in the production of goods which use a more capital-intensive technology, while the capital-poor peripheral countries specialize in more labor-intensive sectors. In this equilibrium, core countries earn more per-capita national income than those in the periphery, which implies the emergence of international UE, with the core exploiting the periphery. Moreover, countries in the periphery are actually worse off in the free trade equilibrium than in autarkic conditions.

Paul Samuelson [27] famously criticized Emmanuel's theory, asserting that countries in the periphery would have no incentives to participate in international trade if their welfare actually declined. To the contrary, all countries would necessarily enjoy mutual gains from trade, due to the principle of comparative advantage. This argument is based on the standard HOS theory by assuming that each country in the periphery has a modern domestic labor market and can freely decide whether or not to participate in trade with core countries. As this assumption is arguably historically inaccurate, his criticism is wide of the mark.

Nonetheless, while Emmanuel's assumptions captured important aspects of the global economy in the first three decades after WWII, they seem less pertinent today, as shown, for example, by the so-called East Asian miracle since the 1970s. The current world economy is still characterized by major wealth inequalities between the global North and the global South, but nowadays countries in the periphery are not necessarily specialized in a monoculture such as coffee or tobacco. ${ }^{2}$ Similarly, although international labor markets remain segmented and institutional differences across countries persist, wage differentials, at least in some areas of the world have been reduced. However, if this description is accurate, it would seem that Emmanuel's theory is no longer relevant to understand the global economy.

In this paper, we provide an appraisal of UE theory in the light of recent contributions asking in particular whether it provides a useful theoretical framework to understand inequalities in a global, competitive economy. As we have just argued, this appraisal is relevant in

\footnotetext{
${ }^{1}$ For more on the world-systems theory, see, for example, Wallerstein ([35], Ch. 7).

${ }^{2}$ In the postwar period, a core-periphery structure consistent with Emmanuel's [9] theoretical approach characterized the relations between the developed Western capitalist countries - with the US as the main hegemonic power - and the underdeveloped former colonial countries. This structure has undergone major transformations after the first oil crisis and the U.S. defeat in the Vietnam War due to geo-political factors and to major innovations in financial technology. In the current regime of economic globalization, some of countries in the periphery have managed to escape their condition of underdevelopment and position themselves as a new frontier of capital accumulation to alleviate the falling profit rates and excess capital in the developed countries. For a thorough discussion, see Arrighi [1].
} 
the light of the recent trends in the world economy. But it is also theoretically important: does the validity of the theory of unequal exchange hinge, crucially, on market imperfections (just like, somewhat paradoxically, neoclassical explanations of inequalities do)? Or can we provide an explanation of UE, and international disparities, that is consistent with the existence of mutual gains from trade between the North and the South countries? This is a key question since, in a Marxian approach noted "a richer country exploits a poorer one, even when the latter benefits from the exchange" (Marx [19], Ch. 20)).

The broader question of the validity, and relevance, of UE theory in the present world can be split into two parts. One concerns the appropriate concept of UE. It is now almost a commonplace, even outside of the mainstream, to consider UE theory logically flawed and essentially metaphysical, largely due to its reliance on the labor theory of value. Even when UE theory is not discarded out of hand due to its alleged conceptual problems, its normative relevance is often questioned. Emmanuel's notion of UE, for example, focuses on the differences between the international prices and (domestic) labor values of commodities, but the normative relevance of this definition is not immediately obvious. Why should such discrepancies be a major concern for socialists? And if such discrepancies obtain only under the restrictive assumptions underlying Emmanuel's approach, shall we conclude that the current global economy - where such assumptions seem much less accurate - is free of UE and exploitation?

The other part concerns the determinants of UE: what are the factors that lead to the emergence, and persistence, of unequal exchange, exploitation, and a hierarchical structure in international relations? Do these phenomena arise from market imperfections, such as imperfect competition, or trade barriers (and would therefore be eliminated by promoting free trade)? Or can they arise in competitive markets, as the product of capitalist relations of production?

In this paper, we review some recent contributions that address the issues of the appropriate definition of UE, its normative relevance, and the determinants of UE exploitation and class.

\section{The economic environment}

Consider a simple international economy with a set $\mathcal{N}=\{1, \ldots N\}$ of countries. A country is generically denoted by $\nu$. For simplicity, we assume that only two goods are produced and traded in internationally competitive markets. They are produced by means of themselves and of one primary factor, namely human labor which is assumed to be homogeneous. ${ }^{3}$

Citizens in each country plan their economic activities over a time horizon consisting of $t=1,2, \ldots, T$ periods. In each period $t$, ${ }^{4}$ we denote by $\boldsymbol{p}_{t}=\left(p_{1, t}, p_{2, t}\right)$ the (row vector of) commodity prices. Because the international goods market is competitive the law of one price holds. We assume that countries can borrow and lend on a perfectly competitive

\footnotetext{
${ }^{3}$ Of course, this is empirically false: both population and human capital vary enormously across countries. Yet none of our conclusions depend on this assumption and the model can be easily generalized to take into account heterogeneous labor endowments.

${ }^{4}$ In what follows, for the sake of notation brevity, we shall write 'at all $t$ ' or 'in each $t$ ' to mean 'for all $t=1, \ldots T^{\prime}$.
} 
international credit market and the equilibrium interest rate in period $t$ is denoted by $r_{t} .^{5}$

In order to abstract from market imperfections and normatively irrelevant sources of heterogeneity, and to investigate the fundamental determinants of UE, we assume conditions of production (available technology) and consumption (evaluation of national welfare) are common to all countries.

\section{$2.1 \quad$ Production}

The production of each good requires as inputs both commodities and labor. All countries can access the same production technology defined as $a_{i j}>0$ and $L_{j}>0$ for $i, j=1,2$, where $a_{i j}$ is the amount of commodity $i=1,2$ necessary as a material input to produce one unit of commodity $j=1,2$ and $L_{j}$ represents the amount of labor time necessary to produce one unit of commodity $j=1,2$. The structure of material inputs necessary for production is denoted by a Leontief matrix of input coefficients, ${ }^{6}$

$$
\boldsymbol{A}=\left[\begin{array}{ll}
a_{11} & a_{12} \\
a_{21} & a_{22}
\end{array}\right],
$$

and the symbol $\boldsymbol{A}_{j}$ denotes the $j$-th column of $\boldsymbol{A}$, namely the structure of inputs in sector $j$. The structure of direct labor inputs is captured by the vector of labor coefficients $\boldsymbol{L}=$ $\left(L_{1}, L_{2}\right)$. This implies that in order to produce an amount $x_{j}$ of good $j$ one needs $\boldsymbol{A}_{j} x_{j}$ units of the two goods and $L_{j} x_{j}$ units of labor as inputs.

Given the Leontief production technique $(\boldsymbol{A}, \boldsymbol{L})$, the labor values of all commodities are given by $\boldsymbol{v} \equiv \boldsymbol{L}(\boldsymbol{I}-\boldsymbol{A})^{-1}>\mathbf{0}$.

Production takes one time period. The amount of output that can be produced in a given period depends on the endowments of the two goods, and labor, available in the economy at the beginning of the period. Available endowments are determined by past decisions to save and accumulate. Formally, at the beginning of period $t$, each country is endowed with a nonnegative commodity bundle $\boldsymbol{\omega}_{t-1}^{\nu}=\left(\omega_{1, t-1}^{\nu}, \omega_{2, t-1}^{\nu}\right)$, which is carried over from the previous period $t-1$, and with one unit of (homogeneous) labor.

\subsection{Behavior}

In order to focus on international trade, we abstract from heterogeneity within countries and assume that all fellow citizens are alike. Therefore the index $\nu$ denotes both a country and what we may consider to be its representative agent. Citizens care about consumption of goods and leisure, and their welfare in a given period is captured by a function that measures the welfare of the representative agent. As already noted, we do not believe that international inequalities are due to differences in preferences that citizens of different countries have concerning consumption and leisure: a higher level of (per capita) income is not due to the natural inclinations and ethics of certain peoples, and conversely poverty does

\footnotetext{
${ }^{5}$ In section 4.1 we consider the emergence of UE in autarky and assume that borrowing and lending takes place only within national borders. In this case, a different interest rate $r_{t}^{\nu}$ will prevail in each country $\nu$.

${ }^{6}$ The notation for vector inequalities is as follows. For any $x=\left(x_{1}, x_{2}\right), y=\left(y_{1}, y_{2}\right): x \geqq y$ if and only if $x_{i} \geqq y_{i}$ for $i=1,2 ; x>y$ if and only if $x_{i}>y_{i}$ for $i=1,2$; and $x \geq y$ if and only if $x \geqq y$ and $x \neq y$.
} 
not stem from the laziness or lack of imagination of the others. Therefore we assume that the one-period welfare function is common to all countries and is given as follows: for every consumption level of commodities $\boldsymbol{c}=\left(c_{1}, c_{2}\right)$ and the leisure hours $1-l$ (total disposable time which is normalized to one unit, say one day, minus labor hours),

$$
u(\boldsymbol{c}, l)=v(\boldsymbol{c})+\phi(1-l),
$$

where $v$ and $\phi$ are increasing in $\boldsymbol{c}$ and $1-l$, respectively. In other words, welfare increases as national income grows and citizens are free from toil. ${ }^{7}$

The welfare of the citizens of a country over their whole life can then be expressed as the sum of the welfare levels attained in every period:

$$
\sum_{t=1}^{T} \rho^{t-1} u\left(\boldsymbol{c}_{t}^{\nu}, l_{t}^{\nu}\right)
$$

where $0<\rho \leqq 1$ is the discount factor, which is common to all countries. If $\rho<1$ then countries have a presentist bias: they prefer to obtain welfare earlier rather than later. If, instead, $\rho=1$ then countries are indifferent between obtaining one unit of welfare today, or in some future period. We take the simplest possible approach by assuming that the behavior of a country can be formulated as an optimization problem where countries choose a set of actions, among those available to them, that maximize their lifetime welfare. ${ }^{8}$

The actions countries undertake include production, lending/borrowing, trading inputs and final goods, work, consumption and saving. In our model, at the end of every $t$, countries decide how much of each good to consume, and how much to invest on capital assets. At the beginning of $t$ they make their production and lending decisions. First, they decide how much of their wealth to lend on the credit market, which we denote by $z_{t}^{\nu}$. Then, they determine their production activities, deciding to produce using their own capital or by borrowing capital abroad. $\boldsymbol{x}_{t}^{\nu}=\left(x_{1 t}^{\nu}, x_{2 t}^{\nu}\right)$ denotes the outputs produced through the former method, and $\boldsymbol{y}_{t}^{\nu}=\left(y_{1 t}^{\nu}, y_{2 t}^{\nu}\right)$ the latter. Countries can also decide to use their wealth at the beginning of $t$ to purchase goods to be sold at the end of $t$, which we denote by $\boldsymbol{\delta}_{t}^{\nu}=\left(\delta_{1 t}^{\nu}, \delta_{2 t}^{\nu}\right)$.

The actions available to countries are constrained by the external economic environment, their own endowments, and past decisions. In the competitive setting countries take the international prices of commodities and their world interest rate as given. ${ }^{9}$ Formally, let the sequence of commodity prices and the international interest rate be denoted by $(\mathbf{p}, \mathbf{r})$, which consists of prices at the initial period $\boldsymbol{p}_{0}$ and the full path of prices and interest rates in all subsequent periods $\left\{\left(\boldsymbol{p}_{t}, r_{t}\right)\right\}_{t=1}^{T} \cdot 10$

\footnotetext{
${ }^{7}$ By assuming that welfare increases in consumption we are abstracting from the problems related to climate change and pollution. These are obviously very important issues, but we can set them aside for the purposes of our investigation.

${ }^{8}$ This is a methodological, rather than ontological, assumption and it simplifies the analysis considerably. The main conclusions, however, can be reached in a more general setting.

${ }^{9}$ Recall that our aim is not to develop an empirical analysis of the world economy. Our aim is to investigate UE theory at the theoretical level while abstracting from certain features of real world interactions, including the actually existing massive asymmetries in economic weight and bargaining power between countries in the international arena.

${ }^{10}$ This implicitly assumes rational expectations and is in line with standard models in the literature (see e.g. Roemer, [24], [25]).
} 
Given the price vector, countries face a number of constraints that define the boundaries of their feasible choices.

(i) At the beginning of period $t$, country $\nu$ owns an amount of wealth (the value of its capital endowments), $\boldsymbol{p}_{t-1} \boldsymbol{\omega}_{t-1}^{\nu}$, which is the result of past decisions. This wealth constitutes the budget that can be lent abroad $\left(z_{t}^{\nu}\right)$, or used either to obtain material inputs to produce outputs $\left(\boldsymbol{p}_{t-1} \boldsymbol{A} \boldsymbol{x}_{t}^{\nu}\right)$, or for the speculative purchase of goods to be sold at the end of the period $\left(\boldsymbol{p}_{t-1} \boldsymbol{\delta}_{t}^{\nu}\right)$;

(ii) At the end of period $t$, each country obtains income by selling its output $\left(\boldsymbol{p}_{t}\left(\boldsymbol{x}_{t}^{\nu}+\boldsymbol{y}_{t}^{\nu}\right)\right)$ and any goods purchased at the beginning of $t$ for speculative purposes $\left(\boldsymbol{p}_{t} \boldsymbol{\delta}_{t}^{\nu}\right)$. In addition, income is obtained when credit contracts are closed and capital and interest are paid back $\left(\left(1+r_{t}\right) z_{t}^{\nu}\right)$. This income can be used to finance consumption expenditure $\boldsymbol{p}_{t} \boldsymbol{c}_{t}^{\nu}$, savings $\boldsymbol{p}_{t} \boldsymbol{\omega}_{t}^{\nu}$, and the repayment of debt $\left(\left(1+r_{t}\right) \boldsymbol{p}_{t-1} \boldsymbol{A} \boldsymbol{y}_{t}^{\nu}\right)$; and

(iii) Total labour spent in productive activities $\left(\boldsymbol{L}\left(\boldsymbol{x}_{t}^{\nu}+\boldsymbol{y}_{t}^{\nu}\right)\right)$ cannot exceed the endowment.

Formally, in any $t$, given a price system $\left(\boldsymbol{p}_{t-1}, \boldsymbol{p}_{t}, r_{t}\right)$, each $\nu$ faces the following constraints:

$$
\begin{gathered}
\boldsymbol{p}_{t-1}\left(\boldsymbol{A} \boldsymbol{x}_{t}^{\nu}+\boldsymbol{\delta}_{t}^{\nu}\right)+z_{t}^{\nu}=\boldsymbol{p}_{t-1} \boldsymbol{\omega}_{t-1}^{\nu} \\
\boldsymbol{p}_{t}\left(\boldsymbol{x}_{t}^{\nu}+\boldsymbol{\delta}_{t}^{\nu}\right)+\left[\boldsymbol{p}_{t} \boldsymbol{y}_{t}^{\nu}-\left(1+r_{t}\right) \boldsymbol{p}_{t-1} \boldsymbol{A} \boldsymbol{y}_{t}^{\nu}\right]+\left(1+r_{t}\right) z_{t}^{\nu}=\boldsymbol{p}_{t}\left(\boldsymbol{c}_{t}^{\nu}+\boldsymbol{\omega}_{t}^{\nu}\right) \\
\boldsymbol{L}\left(\boldsymbol{x}_{t}^{\nu}+\boldsymbol{y}_{t}^{\nu}\right)=l_{t}^{\nu} \leqq 1
\end{gathered}
$$

Finally, in order to fully determine the choices of each country we need to specify a terminal condition constraining choices at the end of the relevant time horizon:

(iv) In the final period $T$, each country $\nu$ leaves an amount of wealth $\left(\boldsymbol{p}_{T} \boldsymbol{\omega}_{T}^{\nu}\right)$ that is at least as large as the amount it inherited, re-evaluated at current prices $\left(\boldsymbol{p}_{T} \boldsymbol{\omega}_{0}^{\nu}\right)$.

Condition (iv) can be interpreted as a statement capturing the bequest motive that characterizes most agents, and every nation. But it can also be considered as a normative condition imposing a sustainability constraint: no country is allowed to deplete the capital stock. Formally:

$$
\boldsymbol{p}_{T} \boldsymbol{\omega}_{T}^{\nu} \geqq \boldsymbol{p}_{T} \boldsymbol{\omega}_{0}^{\nu}
$$

In summary, for a given path of the price vector $\left\{\boldsymbol{p}_{t}\right\}_{t=0}^{T}$ and $\left\{r_{t}\right\}_{t=1}^{T}$, each country $\nu$ chooses a complete plan $\left(\boldsymbol{x}_{t}^{\nu}, \boldsymbol{y}_{t}^{\nu}, z_{t}^{\nu}, \boldsymbol{\delta}_{t}^{\nu}, \boldsymbol{\omega}_{t}^{\nu}\right)$, in order to maximize (1) subject to constraints (2)-(5) and given inherited capital stocks $\boldsymbol{\omega}_{0}^{\nu}$. We denote country $\nu$ 's optimization problem as $M P^{\nu}$ and the maximum lifetime (discounted) welfare that country $\nu$ can obtain if it is endowed with $\boldsymbol{\omega}_{0}^{\nu}$ as $V\left(\boldsymbol{p}_{0} \boldsymbol{\omega}_{0}^{\nu}\right)$. 


\subsection{Reproducible solutions}

In reality the decisions undertaken at the country level are shaped, in part, by international institutions, bilateral and multilateral agreements, international law, and customary normsas well as, at times, coercive means employed by powerful countries. However, abstracting from these myriad geopolitical factors and focusing on purely economic transactions, imperial or subtle neocolonial relations still characterize the extraction of natural resources, production and exchange of goods, and global credit and financial markets.

Of course, if income and welfare inequalities, exploitation, and unequal exchange emerge from the use of brute force, which allows powerful countries to steal from weaker ones; or to compel them to sell at unfairly low prices, then international relations are obviously marred by major injustices. But suppose that agents in international goods and credit markets were subject only to 'the dull compulsion of economic relations' with competitive forces fully at play without any outside interference, while preserving capitalist relations of production. Does the global economy become automatically fair? Or, to put it in a slightly different way, does our indictment of capitalism, and its global reach, depend fundamentally on the presence of force and coercion?

This is not an idle question. If the main injustice of capitalism - and, in the international context, of neocolonial relations - was the use of force, or threat thereof, then one may argue that the key political objective is to even the playing ground, and make sure that no country can, say, invade another. But to enforce peaceful relations is not necessarily to promote a fundamental change in production relations. These are conceptually different objectives and should be analyzed separately.

Hence, in our abstract thought experiment, we shall consider allocations where countries are only subject to the 'dull compulsion of economic relations' and, as a first step in the analysis, we shall focus on competitive allocations. Can UE emerge even in a setting characterised by economic interactions that are only mediated by competitive markets? What are the factors driving exploitative relations in such an abstract setting?

To be specific, we adopt a concept of Marxian equilibrium first proposed by Roemer ([24], [25]), namely the notion of a Reproducible Solution (RS). At any period $t$, let $\boldsymbol{c}_{t}$ denote the aggregate consumption of all countries, and let a similar notation hold for all other aggregate variables $\boldsymbol{x}_{t}, \boldsymbol{y}_{t}, z_{t}, \boldsymbol{\delta}_{t}, \boldsymbol{\omega}_{t}{ }^{11}$ The concept of market equilibrium, RS, relevant for the international economy is defined by the following five conditions.

The first condition concerns the choices of the citizens of each country in isolation, and consistent with our analysis in section 2.2, it stipulates that each country $\nu$ chooses its consumption, saving, and production plans to maximize national welfare - namely, it solves the optimization program $M P^{\nu}$. The following three conditions, instead, stipulate that the actions chosen by the citizens of different countries are compatible in the aggregate.

At the beginning of each period, the aggregate demand of capital goods by all countries, either for productive purposes, or for speculative aims, must not exceed the total supply of capital stocks available globally:

$$
\boldsymbol{A}\left(\boldsymbol{x}_{t}+\boldsymbol{y}_{t}\right)+\boldsymbol{\delta}_{t} \leqq \boldsymbol{\omega}_{t-1}
$$

\footnotetext{
${ }^{11}$ Formally, $\boldsymbol{c}_{t} \equiv \sum_{\nu \in \mathcal{N}} \boldsymbol{c}_{t}^{\nu}$, and likewise for all other variables.
} 
At the end of each period, the aggregate demand of goods for consumption or investment purposes should not exceed aggregate global supply:

$$
\boldsymbol{x}_{t}+\boldsymbol{y}_{t}+\boldsymbol{\delta}_{t} \geqq \boldsymbol{c}_{t}+\boldsymbol{\omega}_{t} .
$$

The international credit market should also clear in every period:

$$
\boldsymbol{p}_{t-1} \boldsymbol{A} \boldsymbol{y}_{t}=z_{t}
$$

Finally, at the end of the planning horizon each country must leave at least as much of its total capital stocks as it inherited:

$$
\boldsymbol{\omega}_{T} \geqq \boldsymbol{\omega}_{0} .
$$

This notion of equilibrium is rather different from the standard neoclassical concepts because the emphasis is on the reproducibility of social and economic relations over time, as captured especially by conditions (7) and (9).

In summary, a RS comprises a price vector $(\mathbf{p}, \mathbf{r})$ specifying commodity prices and the interest rate over the entire horizon and an associated set of actions for all countries that solve the countries maximization programme $M P^{\nu}$ and satisfy conditions (6)-(9).

One important feature of equilibrium prices should be noted at the outset. As we have noted, competitive forces lead to the law of one price to hold in the the credit market, and a unique interest rate prevails in the global economy. However, in a perfectly competitive market, competitive pressures will also lead to the erosion of extra-profits from productive activities, namely profits above and beyond the return on capital lent on the credit market, and all sectors in all countries will earn the same revenue (net of the cost of capital inputs) per unit of labor employed. This leads to a well-known result in international economics, namely the equalization of the prices of factors of production even if they are not mobile across borders. Therefore, letting $w_{t}$ denote the wage rate at $t,{ }^{12}$ at a $\mathrm{RS}$

$$
\boldsymbol{p}_{t}=\left(1+r_{t}\right) \boldsymbol{p}_{t-1} \boldsymbol{A}+w_{t} \boldsymbol{L} .
$$

\section{General Definition of Exploitation}

At the most general level, according to UE theory, exploitative relations are characterized by systematic differences between the amount of labor 'contributed' to the economy, in some relevant sense, and the amount of labor 'received', in some relevant sense. Yet, there are many conceivable ways of defining the labor given and received by agents. In his seminal book on exploitation theory alone, John Roemer examines no fewer than six distinct UE definitions (see Roemer [25]: Part I and pp.121, 132-133, 168), and many other approaches have been proposed in the literature, in addition to those briefly sketched in the Introduction. ${ }^{13}$

Alternative UE definitions may seem to differ for relatively minor, and merely technical details. At a closer look, however, some deep theoretical cleavages emerge and different UE

\footnotetext{
${ }^{12}$ Formally, factor price equalization implies that for any two countries $\nu, \mu \in \mathcal{N}$ and any period $t$, their domestic wage rates are equal $w_{t}^{\nu}=w_{t}^{\mu}=w_{t}$.

${ }^{13}$ The literature is too vast for a comprehensive list of references. Classic contributions include Morishima [22]; Duménil [6]; Foley [13]; Roemer [24]; and Flaschel ([10], [11]). For a discussion, see Yoshihara ([36], $[37])$.
} 
approaches incorporate such distinct normative and positive intuitions that it is legitimate to wonder whether they actually bear any family resemblance. In some approaches, exploitation is defined as a property of economic actors: it measures the status of an actor in the network of labor flows - how much labor the actor contributes to the rest of society and how much labor it receives back. In others, exploitation is primarily a relation between economic actors (e.g. Holmstrom [14], Fleurbaey [12]). The normative content of the notion of UE exploitation is also contested. According to Elster ([8], p.167), "Being exploited means, fundamentally, working more hours than are needed to produce the goods one consumes," and thus exploitative relations are affected by saving/investment decisions. Other authors, instead, emphasize purchasing power and the idea that "workers give more labor to their employers than they receive through the goods their wages can afford" (Fleurbaey [12], p.653), and consumption decisions are irrelevant to define exploitation status. And so on.

In other words, there is no shortage of definitions of UE theory: many different definitions can be, and have in fact been proposed, which incorporate different positive and normative intuitions. Nor is there any shortage of heated debates over which definition is more rigorous, or better incorporates Marxian intuitions, or returns intuitive verdicts in certain cases. Instead of proposing another definition, and defend it on exegetical or empirical grounds, in a series of contributions we have adopted a novel axiomatic approach to exploitation theory. ${ }^{14}$ The fundamental advantage of an axiomatic framework is that it allows one to start from first principles in order to analyze what exploitation is, and how it should be measured. The axiomatic method can thus be used to rigorously and explicitly state the normative and positive foundations of the notion of exploitation, and to precisely identify differences and similarities between alternative approaches.

Veneziani and Yoshihara [34] have identified the core of UE theory that is shared by all of the main approaches in the literature. They have first formalized the (often implicit) intuitions incorporated in the various definitions as separate axioms. Then, they have formulated a single domain condition which summarizes the foundations of UE exploitation theory. The domain axiom, called Labor Exploitation, expresses the following idea: at any allocation, given any definition of exploitation, the exploitation status of every actor is unambiguously determined by comparing the labor contributed to the economy, and the labor received. The former quantity is just a number which captures the amount of labor spent in productive activities. The labor received is a (possibly degenerate) interval and it is determined by identifying two (possibly equal) commodity bundles, which should be affordable and technically feasible, and the labor associated with, or contained in them, which is (a linear transformation of) the labor necessary to produce them as net output. If the labor contributed is more (resp., less) than the maximum (resp., minimum) amount of labor received, then the agent is regarded as exploited (resp., an exploiter). Labor Exploitation sets weak restrictions on the way in which the set of exploiters and the set of exploited agents are identified and it can be shown that all of the main approaches satisfy it.

We can apply this definition to the international context and derive a general approach to defining UE exploitation. Consider a RS with equilibrium prices $(\mathbf{p}, \mathbf{r})$ and the associated actions. In order to define the amount of labor received by a country $\nu$ we shall focus on a normatively relevant set of commodity bundles at period $t$, denoted as $B_{t}$, which

\footnotetext{
${ }^{14}$ See Yoshihara $[36,37]$ and Veneziani and Yoshihara [31, 32, 33, 34].
} 
represents the set of available consumption bundles if country $\nu$ withholds capital stocks $\boldsymbol{p}_{t-1} \boldsymbol{\omega}_{t-1}^{\nu}$ at the beginning of period $t$ for the next period's production. ${ }^{15}$ Then, following Veneziani and Yoshihara $[32,33,34]$, we can state that any UE theory formulates the notion of exploitative relations as follows: in equilibrium, in every period $t$, the mutually disjoint subsets of exploiting and exploited countries are identified by specifying, for each country $\nu$ at most two reference bundles $\underline{\boldsymbol{c}}_{t}^{\nu}, \overline{\boldsymbol{c}}_{t}^{\nu} \in B_{t}$ such that $\boldsymbol{v} \underline{\boldsymbol{c}}_{t}^{\nu} \geqq \boldsymbol{v} \overline{\boldsymbol{c}}_{t}^{\nu}$ and

$$
\begin{aligned}
\nu \quad \text { is a UE exploiter } & \Leftrightarrow l_{t}^{\nu}<\boldsymbol{v} \overline{\boldsymbol{c}}_{t}^{\nu} ; \\
\nu \text { is UE exploited } & \Leftrightarrow l_{t}^{\nu}>\boldsymbol{v} \underline{\boldsymbol{c}}_{t}^{\nu} .
\end{aligned}
$$

In order to interpret the previous definition, recall that the exploitation status of country $\nu$ is determined by the difference between the amount of labor 'contributed' and 'received' by $\nu$. The former quantity is given simply by the amount of labor performed by $\nu$ in productive activities, $l^{\nu}$. But there are many possible views concerning the latter quantity. As a domain condition, the previous definition provides some minimal, key restrictions on the definition of the amount of labor that agents receive.

To be specific, it requires that the exploitation status of each country be determined by identifying two nonnegative vectors $\underline{\boldsymbol{c}}_{t}^{\nu}, \overline{\boldsymbol{c}}_{t}^{\nu}$-call them the exploitation reference bundles (ERBs) - whose labor content, the amount of labor that $\nu$ receives, is the value of the labor necessary to produce the ERB as net output, $\boldsymbol{v} \underline{\boldsymbol{c}}_{t}^{\nu}$ and $\boldsymbol{v} \overline{\boldsymbol{c}}_{t}^{\nu}$. If $\nu$ supplies $l^{\nu}$, and $l^{\nu}$ is more than $\boldsymbol{v} \underline{\boldsymbol{c}}_{t}^{\nu}$, then $\nu$ is regarded as contributing more labor than $\nu$ receives, and is thereby exploited; and similarly for exploiters.

The ERBs must have two properties. First, they must be in principle affordable, at the ruling international prices given the country's decisions and endowments. This embodies the idea that the amount of labor that a country receives depends on national income. In standard approaches, the ERBs coincide and they are equal to the bundle actually chosen by the agent. Our approach here is weaker in that it only requires that the ERBs be potentially chosen.

Second, the ERBs must be technically feasible. This embodies the intuition that the amount of labor received by an agent is related to production conditions. More precisely, the ERBs should be technologically feasible as net output, and their labor content is the amount of labor socially necessary to produce them.

These properties, which can be shown formally to be shared by all of the main approaches, may seem rather weak and undemanding. Yet, perhaps surprisingly, they outline very clear boundaries for the set of admissible definitions of exploitation in the global economy, and provide the conceptual framework to analyze the emergence of exploitative relations in the international context.

In a series of seminal contributions, John Roemer $[25,26]$ has adopted the UE perspective to analyze UE exploitation in the global context and the hierarchical structure of the international economy.

\footnotetext{
${ }^{15}$ To be precise the set should be denoted as $B_{t}\left((\mathbf{p}, \mathbf{r}) ; \boldsymbol{p}_{t-1} \boldsymbol{\omega}_{t-1}^{\nu}, l_{t}^{\nu}\right)$ and is defined formally as follows

$$
B_{t}\left((\mathbf{p}, \mathbf{r}) ; \boldsymbol{p}_{t-1} \boldsymbol{\omega}_{t-1}^{\nu}, l_{t}^{\nu}\right) \equiv\left\{\boldsymbol{c} \in \mathbb{R}_{+}^{2} \mid \boldsymbol{p}_{t} \boldsymbol{c}=\left(1+r_{t}-R_{t}\right) \boldsymbol{p}_{t-1} \boldsymbol{\omega}_{t-1}^{\nu}+w_{t} l_{t}^{\nu}\right\}
$$
}

where $R_{t} \equiv \frac{p_{t} \boldsymbol{\omega}_{t-1}}{\boldsymbol{p}_{t-1} \boldsymbol{\omega}_{t-1}}$ is the inflation rate measured by the total capital stocks as numéraire. 
First, Roemer ([25], Ch. 1) analyzes unequal exchange in a pre-capitalist economy in order to identify the sufficient conditions for the emergence of UE exploitation in the global economy. By means of a numerical example, he shows that, given international inequalities in the ownership of productive assets and a perfectly competitive world market for commodities, international relations are characterized by UE exploitation. Neither international credit markets nor labor glows across borders are necessary.

Roemer [26] then shows that if a global credit market is also present, in the presence of asset inequalities across borders, international relations are characterized both by UE exploitative relations and by a hierarchical structure depending on the position of countries in the credit market. A country's position in the credit market is also correlated to its UE exploitation status.

In terms of the debates sketched in the Introduction, Roemer's [25, 26] results provide some fundamental insights. First, mutual gains from free trade and UE exploitation are not mutually inconsistent. Even without market imperfections and coercion the economic development of less developed countries is crucially dependent on capital exports from developed countries, and surplus is transferred from the former to the latter via international credit markets. Second, the fundamental source of UE exploitation (and classes) is the inequality in the holdings of productive assets.

We analyze the recent literature that reconsiders Roemer ([25], Ch. 1) and Roemer [26], respectively, in the next two sections.

\section{The emergence of international UE}

In this section, we discuss the emergence of UE in international economies without capital mobility across borders focusing on Kaneko and Yoshihara [38, 15]. The starting point of their analysis is that Roemer's [25] numerical example, while insightful, is not a general proof. Kaneko and Yoshihara therefore extend Roemer's work to characterize the necessary and sufficient conditions for the emergence of UE in the pre-industrial world economy.

We consider a special case of the model outline in section 2 by focusing only on two countries, $\mathcal{N}=\{N h, S h\}$, which can be thought of as the global North and the global South. We assume that once countries attain a common minimum consumption standard, which can be thought of as a common subsistence consumption bundle $\boldsymbol{b}>\mathbf{0}$, they are interested simply in minimizing toil. As a result, a country's welfare at $t$ can be expressed as $u(\boldsymbol{c}, l)=1-l$ for any $\boldsymbol{c} \geqq \boldsymbol{b}$. We shall also abstract from time preference and assume $\rho=1$.

Given these simplifying assumptions, the model can be interpreted as portraying a preindustrial world economy, as international financial networks are absent and countries' welfare functions are characterized by a preference for leisure, once a minimum subsistence level is reached. The latter assumption captures some ubiquitous properties of pre-industrial societies before the new time discipline was imposed by the introduction of capitalist relations of production at the end of the Eighteenth century (see Thompson [28], Cunningham [4, 5]. In a pre-capitalist context, economic activity is not driven by capital accumulation, and so no feature of industrial capitalism is observed in equilibrium. 


\subsection{Incompletely specialized equilibria in pre-industrial world economies}

In the pre-industrial world economy, consumption in each country is equal to $\boldsymbol{b}$ and the speculative motive is absent $\left(\boldsymbol{\delta}_{t}=\mathbf{0}\right)$ in equilibrium. Further, there is no international credit market and therefore no lending or borrowing $\left(\boldsymbol{y}_{t}=\mathbf{0}\right.$ and $\left.z_{t}=0\right)$; and labor is immobile. However, labor and capital are traded within each country $\nu$, and their respective prices are the wage rate $w_{t}^{\nu}$ and the interest rate $r_{t}^{\nu}{ }^{16}$

In order to examine the emergence of UE in a situation similar to the standard HOS trade model, Kaneko and Yoshihara [38, 15] focus on RS's with imperfect specialization, in which each country may specialize in the production of one good, but does not produce only that good $\left(\boldsymbol{x}_{t}^{\nu}>\mathbf{0}\right)$. Under these assumptions, competition on international commodities markets leads to factor price equalization: the wage rates and interest rates in all countries are equal $\left(w_{t}^{N h}=w_{t}^{S h}=w_{t}\right.$ and $r_{t}^{N h}=r_{t}^{S h}=r_{t}$, all $\left.t\right)$ if, at $t=0$, the organic composition of capital is different in the two sectors. ${ }^{17}$

Therefore under these conditions, and assuming initial prices to be strictly positive, the equilibrium price vector will be given by equation (10). Moreover, it can be shown that in every period $t, w_{t}=\left(1+r_{t}\right) w_{t-1}$ and the real interest rate (that is, the nominal interest rate minus the inflation rate) is always positive: $\boldsymbol{\Pi}_{t} \equiv\left(1+r_{t}\right) \boldsymbol{p}_{t-1}-\boldsymbol{p}_{t} \geq \mathbf{0}$ at every $t$, provided initial prices $\boldsymbol{p}_{0}$ are not proportional to labor values.

Finally, a RS in this economy exists only if the initial aggregate capital stocks $\boldsymbol{\omega}_{0}$ are sufficient to ensure that all countries reach subsistence. Let $\overline{\boldsymbol{\omega}}$ be the vector identifying the minimum level of capital in both sectors that allows both countries to reach subsistence. We shall assume that $\boldsymbol{\omega}_{0}=\overline{\boldsymbol{\omega}}^{18}$

\subsection{Characterization for the emergence of UE}

In the pre-industrial world economy, the general approach described in section 3 reduces to the standard definition: country $\nu$ is an exploiter (exploited) at period $t$ if and only if it works less (more) than the socially necessary labor time of the bundle $\boldsymbol{b}: \boldsymbol{L} \boldsymbol{x}_{t}^{\nu}<\boldsymbol{v b}\left(\boldsymbol{L} \boldsymbol{x}_{t}^{\nu}>\boldsymbol{v} \boldsymbol{b}\right) .{ }^{19}$

Assume that the North is richer than the South in the initial period: $\boldsymbol{\omega}_{0}^{N h} \geq \boldsymbol{\omega}_{0}^{S h}$, where $\boldsymbol{\omega}_{0}^{N h}+\boldsymbol{\omega}_{0}^{S h}=\boldsymbol{\omega}_{0}=\overline{\boldsymbol{\omega}}$. Kaneko and Yoshihara [38, 15] show that in equilibrium the North exploits the South at period $t$ if and only if

$$
\left(1+r_{t}\right) \boldsymbol{p}_{t-1} \boldsymbol{\omega}_{t-1}^{N h}-\boldsymbol{p}_{t} \boldsymbol{\omega}_{t}^{N h}>\boldsymbol{\Pi}_{t}(\overline{\boldsymbol{\omega}} / 2)>\left(1+r_{t}\right) \boldsymbol{p}_{t-1} \boldsymbol{\omega}_{t-1}^{S h}-\boldsymbol{p}_{t} \boldsymbol{\omega}_{t}^{S h} .
$$

In order to interpret the latter expression recall that $\boldsymbol{\Pi}_{t}$ can be interpreted as the real interest rate on assets. Therefore the second term represents the real interest revenue at period $t$

\footnotetext{
${ }^{16}$ Thus, conditions (2) and (3) reduce to (1) $\boldsymbol{p}_{t-1}\left(\boldsymbol{A} \boldsymbol{x}_{t}^{\nu}+\boldsymbol{\delta}_{t}^{\nu}\right)=\boldsymbol{p}_{t-1} \boldsymbol{\omega}_{t-1}^{\nu}$; and (2) $\boldsymbol{p}_{t}\left(\boldsymbol{x}_{t}^{\nu}+\boldsymbol{\delta}_{t}^{\nu}\right)=\boldsymbol{p}_{t} \boldsymbol{c}_{t}^{\nu}+$ $\boldsymbol{p}_{t} \boldsymbol{\omega}_{t}^{\nu}$. The relevant conditions of a RS are modified accordingly.

${ }^{17}$ Formally, $\frac{p_{10} a_{11}+p_{20} a_{21}}{L_{1}} \neq \frac{p_{10} a_{12}+p_{20} a_{22}}{L_{2}}$.

${ }^{18}$ Formally, a necessary condition for the existence of a RS is $\boldsymbol{\omega}_{0} \geqq \boldsymbol{A}(\boldsymbol{I}-\boldsymbol{A})^{-1}(2 \boldsymbol{b})$, where the right hand side of the latter inequality represents the minimal capital stocks necessary for the production of $2 \boldsymbol{b}$ as net output. Therefore $\overline{\boldsymbol{\omega}} \equiv \boldsymbol{A}(\boldsymbol{I}-\boldsymbol{A})^{-1}(2 \boldsymbol{b})$. It can be shown that $\boldsymbol{\omega}_{t} \geqq \overline{\boldsymbol{\omega}}$ for every $t$, and in the limit capital stocks would converge to $\overline{\boldsymbol{\omega}}$ in equilibrium. Therefore, the assumption $\boldsymbol{\omega}_{0}=\overline{\boldsymbol{\omega}}$ is without loss of generality and it guarantees that $\boldsymbol{\omega}_{t}=\overline{\boldsymbol{\omega}}$ holds at all $t$ in a RS.

${ }^{19}$ In other words, $\underline{\boldsymbol{c}}_{t}^{\nu}=\overline{\boldsymbol{c}}_{t}^{\nu}=\boldsymbol{b}$ for any $\nu$ at all $t$.
} 
corresponding to an egalitarian distribution of assets. Thus, a country $\nu$ is an exploiter (exploited) at $t$ if and only if $\nu$ 's real interest revenue is higher (lower) than the egalitarian benchmark at $t$.

This confirms and extends Roemer's result: exploitative relations arise from asset inequalities if countries trade in perfectly competitive goods markets. The adoption of a dynamic perspective, however, allows Kaneko and Yoshihara [15] to address an equally important issue that was obscured in Roemer's [24, 25] static, one-period models: are asset inequalities and competitive goods markets sufficient for exploitative relations to persist? This question was already answered in the negative by Veneziani $[29,30]$ in the analysis of rather different models of national economies: asset inequalities and competitive markets (including a competitive labor market) are not sufficient to persist if agents do not discount the future. ${ }^{20}$

Kaneko and Yoshihara [15] confirm and extend this insight. Given $\rho=1$, exploitation decreases over time and disappears as $t$ goes to infinity, with both countries working the same amount of time $(\boldsymbol{v} \boldsymbol{b})$ in the limit. This happens either because commodity prices converge to the labor value pricing, or because each country's capital stocks converges to the world average.

This result raises some doubts on the key conclusions of Roemer's theory and raises the issue of the determinants of exploitative relations in the international economy. We shall return to it in the concluding section.

\section{Class and Exploitation with free capital mobility}

Roemer's [26] conclusions depend on a specific definition of UE-exploitation and are derived in the context of a static, one-period economy with rather specific assumptions on technology and preferences. Veneziani and Yoshihara [33] set up a dynamic model of a global economy that significantly generalizes Roemer [26] in terms of the assumptions on preferences and technology, and of the set of equilibria considered, and consider a whole class of definitions of UE-exploitation consistent with the approach laid out in section 3. Their basic insights can be illustrated in the simpler context laid out in section 2 .

\subsection{The emergence of class division}

Consider the general model outlined in section 2. Can a hierarchical structure emerge, in equilibrium, in the global economy with a competitive credit market? Will a core-periphery dynamic emerge endogenously from financial interactions only? Following Roemer [26], we define four categories that identify a country's position in the global economy based on their optimal actions in the credit market.

In each period $t$, a country is a capital exporter if it can optimize without relying on foreign borrowing, while lending to other countries; it is autarkic if it does not need to

\footnotetext{
${ }^{20}$ Cogliano, Veneziani, and Yoshihara [2] develop a many-agent computational simulation to explore technical change and different distributions of bargaining power as causes of the persistence of exploitation and class relations in accumulating economies. Using a similar framework, Cogliano et al. [3] examine the normative aspects of using redistributive taxes to achieve desirable distributions of assets that result in low levels of inequality or the elimination of exploitation.
} 
borrow or lend to optimize; it is a capital importer if it is at least partially dependent on foreign capital; and it is underdeveloped if it is completely dependent on foreign capital and cannot produce anything on its own. In each period countries fall into one, and exactly one of these categories, which can be denoted respectively as the sets $C_{t}^{1}, C_{t}^{2}, C_{t}^{3}, C_{t}^{4}{ }^{21}$ Countries in $C_{t}^{1}$ and in $C_{t}^{3} \cup C_{t}^{4}$ can be interpreted as the core and the periphery, respectively.

Veneziani and Yoshihara ([33], Theorem 1) show that in equilibrium in every period $t$, a country's class is determined by the monetary value of its capital stocks at the beginning of the period, $\boldsymbol{p}_{t-1} \boldsymbol{\omega}_{t-1}^{\nu}$ and call the result the Dependency School Theorem. The result proves that rich enough countries increase their welfare by exporting their capital and belong to $C_{t}^{1}$, while less developed countries without sufficient assets have to borrow on international markets in order to finance their production. This implies that mutual gains from trade for all countries coexist with a core-periphery structure in which the economic development of the poorer countries depends on capital imports from the richer countries.

\subsection{The relation between UE exploitation and class}

One of the key principles of Marxian political economy is the idea that class and exploitation status are strictly related. This view can be interpreted as a key axiom of the Marxian analysis of unequal exchange, and Roemer has christened it the class-exploitation correspondence principle (CECP). The CECP states that in equilibrium at all $t$ every capital exporter in $C_{t}^{1}$ (capital importer in $C_{t}^{3} \cup C_{t}^{4}$ ) is an exploiter (exploited).

It is not a priori obvious that the CECP will hold for an arbitrary definition of UE exploitation. Indeed, the concept of UE exploitation defined in section 3 provides one perspective to look at international relations focusing on labor flows across borders. The concept of class outlined in section 5.1 provides an alternative perspective focusing instead on financial flows. In principle, there is no reason why the two perspectives should return the same verdict on the structure of international relations.

Is there a definition of UE exploitation consistent with the framework laid out in section 3 such that the CECP generically holds true in the international economy? Veneziani and Yoshihara [33] prove that there exists an entire class of definitions that satisfy the properties in section 3 such that the CECP holds, including, importantly, a definition of exploitation based on the so-called 'New Interpretation' proposed by Duménil [6, 7] and Foley [13]. In this approach, $\overline{\boldsymbol{c}}_{t}^{\nu}=\underline{\boldsymbol{c}}_{t}^{\nu}=\tau_{t}^{\nu} \boldsymbol{c}_{t}$, where $\tau_{t}^{\nu}$ is country $\nu$ 's share of global income, ${ }^{22}$ and country $\nu$ is an exploiter (exploited) if and only if $l_{t}^{\nu}<\boldsymbol{v} \tau_{t}^{\nu} \boldsymbol{c}_{t}\left(l_{t}^{\nu}>\boldsymbol{v} \tau_{t}^{\nu} \boldsymbol{c}_{t}\right)$. In other words, a country is UE-exploiting if the amount of labor contained, or embodied, in its income is higher than the amount of labor performed by its citizens.

But this implies that, contrary to the received view, there exists a definition of unequal exchange that is logically consistent and that, far from being metaphysical, is based on empirically observable magnitudes. If this definition-whose intellectual origins can be traced back to Duménil $[6,7]$ and Foley [13] —is adopted, then a number of key insights of UE-exploitation theory hold: richer core countries can promote capital exports and exploit

\footnotetext{
${ }^{21}$ Formally, at $t: \nu \in C_{t}^{1}$ if it has a solution of $M P^{\nu}$ such that $\boldsymbol{x}_{t}^{\nu} \geq \mathbf{0}, \boldsymbol{y}_{t}^{\nu}=\mathbf{0}, z_{t}^{\nu}>0 ; \nu \in C_{t}^{2}$, if $\boldsymbol{x}_{t}^{\nu} \geq \mathbf{0}$, $\boldsymbol{y}_{t}^{\nu}=\mathbf{0}, z_{t}^{\nu}=0 ; \nu \in C_{t}^{3}$ if $\boldsymbol{x}_{t}^{\nu} \geq \mathbf{0}, \boldsymbol{y}_{t}^{\nu} \geq \mathbf{0}, z_{t}^{\nu}=0$; and $\nu \in C_{t}^{4}$ if $\boldsymbol{x}_{t}^{\nu}=\mathbf{0}, \boldsymbol{y}_{t}^{\nu} \geq \mathbf{0}, z_{t}^{\nu}=0$.

${ }^{22}$ Formally, $\tau_{t}^{\nu} \equiv \frac{\left(1+r_{t}-R_{t}\right) \boldsymbol{p}_{t-1} \boldsymbol{\omega}_{t-1}^{\nu}+w_{t} l_{t}}{\boldsymbol{p}_{t}(\boldsymbol{I}-\boldsymbol{A})\left(\boldsymbol{x}_{t}+\boldsymbol{y}_{t}\right)}$, for any $\nu \in \mathcal{N}$.
} 
poorer countries in the periphery which need capital imports to improve their lot. As in the classical theory of UE, global competitive markets enforce a transfer of labor from developing countries to developed ones.

\section{Conclusions}

This paper shows that the news of the death of UE theory is wildly exaggerated. Logically consistent and theoretically robust definitions of UE exploitation exist that preserve the fundamental insights of the Marxian analysis of unequal exchange in the international arena. If these definitions are adopted, it is possible to prove that exploitative international relations emerge in the world economy via trade in competitive international trade in commodities. If a global credit market also exists, this creates a structure of international relations characterised by a core-periphery structure, whereby richer countries act as capital exporters and poorer countries need to borrow in order to improve their lot. Moreover, the position of a country in the international hierarchy is correlated with its exploitation status: richer countries exploit poorer ones thanks to their dominant position in the credit market.

One important insight of the paper is that international relations need not be characterized by force or massive distortions in order to be marred by major injustices and UE exploitation. The sheer force of the competitive mechanism, together with capitalist property relations, is enough for exploitation and class to emergence in the international context. As we noted in section 4.2, it is unclear whether competition and international asset inequalities are also sufficient for these phenomena to persist as this result hinges on the existence of a positive rate of time preference.

To be sure, it may be argued that this is an empirical matter and perhaps it is plausible to assume $\rho<1$, in which case exploitation does persist indefinitely. Besides, even if $\rho=1$, exploitative relations, once generated, do not disappear completely in every period - though the economy approaches a non-exploitative allocation as $t$ goes to infinity. Nonetheless, an explanation of the persistence of UE exploitation that crucially hinges on subjective time preferences may be deemed unsatisfactory, and perhaps our results suggest that other factors - such as asymmetries in bargaining power- should be brought into play in order to provide a complete theory of UE.

Showing the logical consistency and theoretical robustness of UE theory is a preliminary step in a broader research agenda-important, but preliminary. Hopefully our discussion shows that it is worth pursuing it.

\section{References}

[1] Arrighi, G. (1994). The Long Twentieth Century: Money, Power and the Origins of Our Times. London: Verso.

[2] Cogliano, J.F., Veneziani, R., Yoshihara, N. (2016). The Dynamics of Exploitation and Class in Accumulation Economies, Metroeconomica 67, pp. 242-290. 
[3] Cogliano, J.F., Veneziani, R., Yoshihara, N. (2019). Exploitation, skills, and inequality. Review of Social Economy 77, pp. 208-249.

[4] Cunningham, H. (1980). Lecture in the Industrial Revolution: c.1780-c.1880. New York: St. Martin's Press.

[5] Cunningham, H. (2014). Time, Work and Leisure: Life changes in England since 1700. Manchester: Manchester University Press.

[6] Duménil, G. (1980). De la Valeur aux Prix de Production. Paris: Economica.

[7] Duménil, G. (1984). The So-Called "Transformation Problem" Revisited: A Brief Comment, Journal of Economic Theory 33, pp. 340-348.

[8] Elster, J. (1985). Making Sense of Marx. Cambridge, UK: Cambridge University Press.

[9] Emmanuel, A. (1972). Unequal Exchange. New York: Monthly Review Press.

[10] Flaschel, P. (1983). Actual labor values in a general model of production, Econometrica 51, pp. 435-454.

[11] Flaschel, P. (2010). Topics in Classical Micro- and Macroeconomics. New York: Springer.

[12] Fleurbaey, M. (2014). The facets of exploitation, Journal of Theoretical Politics 26, pp. 653-676.

[13] Foley, D.K. (1982). The Value of Money, the Value of Labor Power, and the Marxian Transformation Problem, Review of Radical Political Economics 14, pp. 37-47.

[14] Holmstrom, N. (1977). Exploitation, Canadian Journal of Philosophy 7, pp. 353-369.

[15] Kaneko, S. and N. Yoshihara (2019). On the General Impossibility of Persistent Unequal Exchange Free Trade Equilibria in the Pre-industrial World Economy, Working Paper 2019-05, UMass Amherst Economics Papers.

[16] Krugman, P. (1981). Trade, Accumulation, and Uneven Development, Journal of Development Economics 8, pp. 149-161.

[17] Maddison, A. (2001). The World Economy. Paris: OECD.

[18] Marx, K. (1954). Capital. A Critique of Political Economy, Vol. I. London: Lawrence \& Wishart.

[19] Marx, K. (1968). Theories of Surplus Value, Vol.III. London: Lawrence \& Wishart.

[20] Matsuyama, K. (2004). Financial Market Globalization, Symmetry-breaking and Endogenous Inequality of Nations, Econometrica 72, pp. 853-884.

[21] Morishima, M. (1973). Marx's Economics. Cambridge, UK: Cambridge University Press. 
[22] Morishima, M. (1974). Marx in the Light of Modern Economic Theory, Econometrica 42, pp. 611-632.

[23] Ricardo, D. (1951). On the Principles of Political Economy and Taxation, in Sraffa, P. (ed.), The Works and Correspondence of David Ricardo, vol. I. Cambridge, UK: Cambridge University Press.

[24] Roemer, J.E. (1981). Analytical Foundations of Marxian Economic Theory. Cambridge, MA: Harvard University Press.

[25] Roemer, J.E. (1982). A General Theory of Exploitation and Class. Cambridge, MA: Harvard University Press.

[26] Roemer, J.E. (1983). Unequal Exchange, Labor Migration and International Capital Flows: A Theoretical Synthesis, Marxism, Central Planning and the Soviet Economy: Economic Essays in Honor of Alexander Erlich (Padma Desai, ed.). Cambridge, MA: MIT Press.

[27] Samuelson, P. (1976). Illogic of Neo-Marxian Doctrine of Unequal Exchange, in Belsley, D. A. et al. (eds.), Inflation, Trade and Taxes: Essays in Honour of Alice Bourneuf. Columbus: Ohio State University Press.

[28] Thompson, E.P. (1967). Time, Work-Discipline, and Industrial Capitalism, Past \& Present 38, pp. 56-97.

[29] Veneziani, R. (2007). Exploitation and Time, Journal of Economic Theory 132, pp. 189-207.

[30] Veneziani, R. (2013). Exploitation Inequality and Power, Journal of Theoretical Politics 25 , pp. 526-545.

[31] Veneziani, R. and N. Yoshihara (2015). Exploitation in Economies with Heterogeneous Preferences, Skills and Assets: An Axiomatic Approach, Journal of Theoretical Politics 27, pp. 8-33.

[32] Veneziani, R. and N. Yoshihara (2017a). One million miles to go: taking the axiomatic road to defining exploitation, Cambridge Journal of Economics 41, pp. 1607-1626.

[33] Veneziani, R. and N. Yoshihara (2017b). Globalisation and Inequality in a Dynamic Economy: An Axiomatic Analysis of Unequal Exchange, Social Choice and Welfare 49, pp. $445-468$.

[34] Veneziani, R. and N. Yoshihara (2018). The theory of exploitation as the unequal exchange of labour, Economics and Philosophy 34, pp. 381-409.

[35] Wallerstein, I. (2011). The Modern World-System I: Capitalist Agriculture and the Origins of the European World-Economy in the Sixteenth Century (New Edition). Berkeley: University of California Press. 
[36] Yoshihara, N. (2010). Class and Exploitation in General Convex Cone Economies, Journal of Economic Behavior 85 Organization 75, pp. 281-296.

[37] Yoshihara, N. (2017). A Progress Report on Marxian Economic Theory: On the Controversies in Exploitation Theory since Okishio (1963), Journal of Economic Surveys 31, pp. 632-659.

[38] Yoshihara, N. and S. Kaneko (2016). On the Existence and Characterization of Unequal Exchange in the Free Trade Equilibrium, Metroeconomica 67, pp. 210-241. 